\title{
A visão de usuários, familiares e profissionais acerca do empoderamento em saúde mental
}

I Tarcísia Castro Alves, ${ }^{2}$ Walter Ferreira de Oliveira, ${ }^{3}$ Eduardo Mourão Vasconcelos I

Resumo: Este trabalho pretendeu investigar o conceito de empoderamento reconhecido pelos principais atores envolvidos no cuidado em saúde mental em dois serviços de atenção psicossocial, como forma de contribuir para a avaliação da identificação, caracterização e apropriação dos dispositivos de empoderamento no processo de Reforma Psiquiátrica no país. Como campo de pesquisa, foram selecionados um Centro de Atenção Psicossocial e um Centro de Convivência, ambos do município de CampinasSP, realizando-se coleta de dados após a aprovação do Comitê de Ética em Pesquisa da Universidade Federal de Santa Catarina. Os sujeitos da pesquisa foram sete usuários, três familiares e 24 profissionais da equipe multiprofissional. $\mathrm{O}$ estudo de caso tomou a forma de pesquisa descritiva e qualitativa. Como resultados, verificou-se que o conceito de empoderamento apresentado por usuários, familiares e profissionais vislumbra a autonomia dos usuários e familiares, perpassando o poder de escolha, o poder de decisão e o poder de serem sujeitos com suas diversidades e semelhanças. Espera-se que este trabalho contribua para a compreensão da importância do empoderamento na reinserção das pessoas em sofrimento mental, servindo como caminho possível para que as realidades de cuidado desenvolvidas nos CAPS espalhados pelo Brasil sejam modificadas.

> Palavras-chave: empoderamento; dispositivos; saúde

\author{
1 Departamento de Ciências \\ da Saúde da Universidade \\ Federal de Santa Catarina \\ (UFSC). Endereço eletrônico: \\ tarcycastroalves@gmail.com \\ 2 Departamento de Ciências \\ da Saúde da UFSC. Endereço \\ eletrônico: walteroliveira.ufsc@ \\ gmail.com \\ ${ }^{3}$ Departamento de Serviço \\ Social da Universidade \\ Federal do Rio de Janeiro \\ (UFRJ). Endereço eletrônico: \\ emvasconcelos55@gmail.com
}


No Brasil, o projeto da Reforma Sanitária foi propulsor da construção de uma reformulação do campo do saber em saúde, uma estratégia política de luta pela democracia, portanto, de reconstrução, em novas bases, da relação entre Estado e sociedade (FLEURY, 2009). Segundo Vasconcelos (2003), uma perspectiva muito própria de empoderamento foi construída durante o período da reforma, sendo também incorporado na Constituição Federal de 1988, assim como na própria legislação e estrutura do atual Sistema Único de Saúde (SUS).

O empoderamento parte de uma construção recente no campo da saúde mental e da Reforma Psiquiátrica, mas se reporta a noções de distintos campos do conhecimento, tendo suas raízes nas lutas pelos direitos civis e sociais, desde o início do Período Moderno, e no movimento feminista e outros movimentos sociais populares da segunda metade do século XX. Na saúde mental, o conceito de empoderamento é tido como o fortalecimento do poder, participação e organização dos usuários e familiares no âmbito do cuidado nos serviços substitutivos e também nas estratégias de defesa de direitos e no exercício do controle e da militância social (VASCONCELOS, 2008b).

Laverack e Labonte (2000) definem o empoderamento como o meio pelo qual as pessoas adquirem maior controle sobre as decisões que afetam suas vidas; ou como mudanças em direção a uma maior igualdade nas relações sociais de poder. Vasconcelos (2003, p. 20) define empoderamento como "o aumento do poder pessoal e coletivo de indivíduos e grupos sociais nas relaçôes interpessoais e institucionais, principalmente daqueles submetidos a relaçôes de opressão e dominação social". Segundo Neves e Cabral (2008), estar empoderado caracteriza-se na liberdade como uma forma de tomar suas próprias decisões, desde que esteja imbuído de informações para isso.

$\mathrm{O}$ empoderamento tem assumido significações que se referem ao desenvolvimento de potencialidades, aumento de informação e percepção, com o objetivo de que exista uma participação real e simbólica que possibilite a democracia (WENDHAUSEN; BARBOSA; BORBA, 2006). Dessa forma, com foco em mudanças e fortalecimento de grupos e indivíduos, os dispositivos de empoderamento em saúde mental tornam-se fatores importantes para a criação de autonomia e reinserção social. 
Reforçando essa participação, a Política Nacional de Promoção da Saúde traz entre seus objetivos a ampliação da autonomia e da corresponsabilidade de sujeitos e coletividades, inclusive o poder público no cuidado integral à saúde, e a minimização e/ou extinção das desigualdades de toda e qualquer ordem (BRASIL, 2006a). Nessa perspectiva, autonomia refere-se à capacidade do sujeito de buscar orientação a suas ações por si mesmo, e com independência, sendo comum a expressão direcionar-se ao indivíduo, às instituições e à comunidade (SANT'ANA, 2009).

A Política Nacional de Saúde Mental, por sua vez, considera o empoderamento um dos seus desafios, bem como a consolidação e ampliação da rede de atenção de base comunitária e territorial, promotora da reintegração social e da cidadania (BRASIL, 2005). Embora o documento da política não tenha disposto objetivamente sobre o empoderamento, aborda-o, implicitamente, como um instrumento de reinserção social, autonomia e promoção da saúde mental.

Entretanto, no processo de mudanças e avanços na saúde mental, o empoderamento é trazido de forma clara no Relatório Final da IV Conferência Nacional de Saúde Mental, realizada no ano de 2010, no eixo III - Direitos Humanos e cidadania como desafio ético e intersetorial, sub eixo 3.7 Organização e mobilização dos usuários e familiares em saúde mental, em que, além de trazer o termo "empoderamento", apresenta maneiras de alcançá-lo, como por exemplo, através do aumento da autonomia e autoestima; pelo estímulo à criação de projetos com o protagonismo dos usuários e familiares; pela criação de cartilhas informativas que esclareçam os direitos e deveres das pessoas com transtorno mental; pela garantia e fortalecimento das associações e cooperativas de usuários e familiares, dentre outros (BRASIL, 2010).

Nessa perspectiva, busca-se o desenvolvimento de uma consciência crítica (FREIRE, 1980) envolvendo o entendimento de como as relaçôes de poder na sociedade moldam as experiências e percepçóes de cada pessoa, e de poder identificar como cada um pode ter um papel dentro de uma mudança social. Isto é particularmente importante em situações de opressão, discriminação, desigualdade e assujeitamento, a partir das quais os indivíduos internalizam crenças e representações de invalidação sobre sua própria identidade e poder.

Apesar das diversas discussões que tomam essa definição, ao se tratar do empoderamento em saúde mental, percebe-se que sua consolidação na prática 
ainda enfrenta obstáculos, representados, entre outros fatores, por questōes de natureza epistemológica e institucional, bem como inflexôes de natureza política e ideológica. Suas abordagens e análises não constituem tarefa fácil, devido às peculiaridades do campo da Saúde Mental, particularmente sua longa história de segregação e exclusão social, o que tende a levar seus atores a reproduzir os valores e práticas mais sedimentados e convencionais.

É dentro desse contexto que ratificamos a relevância do empoderamento enquanto estratégia de promoção da autonomia do sujeito e sua reinserção social. Diante desse cenário, observamos a importância de se compreender que concepções de empoderamento são construídas pelos principais atores da Reforma Psiquiátrica, ou seja, os usuários, seus familiares e profissionais da rede de saúde mental, o que se tornou objetivo da pesquisa que constitui a fonte do presente artigo.

\section{Metodologia}

Nossas vivências e inquietações nos levam à realização de pesquisas, à investigação, à busca de respostas, revelaçôes, descobertas. Logo, esse compromisso nos levou a pautar nosso trabalho em uma pesquisa descritiva com uma abordagem qualitativa, visando observar, registrar, analisar e correlacionar fenômenos ou fatos, sem interferir intencionalmente no ambiente analisado. Utilizamos, para analisar os dados, uma sistematização temática descritiva a partir de categorias básicas, similares aos métodos formais de Análise de Conteúdo. Esta se faz recorrente na pesquisa qualitativa, permitindo ler e interpretar o conteúdo de toda a classe de documentos que, após analisados adequadamente, permitem o acesso ao conhecimento de aspectos e fenômenos da vida social de outro modo inacessível (OLABUENAGA; ISPIZÚA, 1989).

A pesquisa ${ }^{1}$ teve como cenário o Centro de Atenção Psicossocial (CAPS) III da cidade de Campinas-SP, município brasileiro que é um dos modelos de referência no projeto de atenção à saúde mental. Escolhemos esse cenário pelo fato de esse serviço trazer novas abordagens de cuidados às pessoas com transtornos mentais graves, dispositivo central da Reforma Psiquiátrica e a grande aposta para o atendimento dessa população. 
Os critérios para definição dos sujeitos consideraram inicialmente:

1. Em relação aos usuários e familiares - vinculação ao serviço por dois anos ou mais; ser indicação dos profissionais, gestor e/ou indicação dos próprios e usuários e familiares; desejar participar do estudo.

2. Em relação aos profissionais - experiência de trabalho no CAPS de dois anos ou mais; engajamento no movimento antimanicomial; desejar participar do estudo.

Dessa forma, sem contato prévio/vínculo com a pesquisadora, participaram da pesquisa sete usuários; três familiares e 24 profissionais, um dos quais o coordenador do CAPS. Para coletar os dados, foram utilizadas técnicas específicas para cada grupo. Usuários e familiares participaram de entrevistas semiestruturadas individualizadas.

As entrevistas foram realizadas em espaços diversos, dentro e fora do CAPS III, onde utilizamos para o contato com os profissionais e usuários: sala de reuniôes de equipe, sala de acolhimento, salas de oficinas e grupos terapêuticos e com os familiares o contato foi realizado na residência do usuário, sem a presença do mesmo.

No grupo dos profissionais, foram realizadas tanto entrevistas coletivas, no formato de roda de conversa, quanto individualizadas. Participaram da entrevista individual a coordenação do CAPS e dois profissionais da unidade que não puderam participar da roda de conversa. Os demais profissionais participaram apenas da roda de conversa.

A pesquisa foi submetida ao Comitê de Ética e Pesquisa (CEP), da Secretaria Municipal de Saúde de Campinas/SP e da Universidade Federal de Santa Catarina (UFSC). Analisado sob o aspecto ético-legal, o projeto atendeu à Resolução do Conselho Nacional de Saúde n. 196/96, que regulamenta a pesquisa com seres humanos. Os participantes foram informados sobre o tema e os objetivos do estudo e convidados a participar do processo, sendo solicitada sua autorização através da assinatura do termo de consentimento livre e esclarecido para proceder às entrevistas e gravações.

As entrevistas foram codificadas e classificadas seguindo a ordem cronológica em que foram realizadas: U - referindo-se usuários; F - referindose aos familiares; os profissionais foram enumerados PI - para as entrevistas 
individuais e as entrevistas em roda de conversa foram sinalizadas com PM, respeitando-se somente a ordem de ocorrência, sem a preocupação com a identificação individual dos participantes.

\section{Análise e discussão}

Apesar da complexidade do termo, a definição de "empoderamento" foi apresentada pelos usuários e familiares conforme suas vivências no cotidiano, suas experiências de vida, fazendo-os ter um ponto de vista diferenciado dos conceitos e abordagens indicadas pelos profissionais, que as apresentaram de forma elaborada e, por vezes, extrapolaram a definição trazida por alguns autores. Nessa perspectiva, dividimos a apresentação do conceito em dois grupos: o primeiro trazendo os relatos dos usuários e familiares, e o segundo, as falas dos profissionais.

\section{Empoderamento na visão dos usuários e familiares}

Identificamos na explanação e relato dos usuários e familiares acerca da definição de empoderamento, alguns eixos de compreensão que foram categorizados da seguinte forma: 1) cuidado de si; 2) recuperação/sociabilização; 3) militância e crítica ao passado manicomial; 4) ajuda mútua/coletivização.

\section{Empoderamento: experiência e bagagem a respeito da doença}

A visão dos usuários acerca do empoderamento surge como reflexões que perpassam pela independência e liberdade, pelo conhecimento, informação e capacitação e pelo desenvolvimento do autocuidado, do cuidado de si.

[...] empoderamento para mim é me capacitar, adquirir experiência e bagagem a respeito da minha doença para que eu seja uma pessoa livre, uma pessoa autônoma, livre, dona de si mesmo, dona da minha responsabilidade. [...] o que me empodera é o remédio, só que a atividade ajuda porque faz o meu cérebro voltar ao normal. [...] atividade deve ensinar e possibilitar a gente a aprender e se sentir útil para aquilo; é possibilitar minha aproximação com toda a equipe a partir das referências, para que eu possa conversar com o meu psiquiatra sobre os meus medicamentos; é poder fazer o que a gente gosta - futebol; possibilitar a informação para termos conhecimento do nosso problema e dos medicamentos que tomamos; permitir que a gente se expresse baseado no nosso ponto de vista, na nossa experiência de vida. (U1).

[...] é poder, autonomia eu acho que é isso. Autonomia, independência, viver, né, viver. Ah! Na minha vida mesmo. Eu tenho problema de esquizofrenia há 15, 16 anos e estou há quase dez anos bem de saúde graças a Deus, tomo os meus remédios, eu mesmo tomo conta dos meus remédios, quanto minha terapia, que nem amanhã mes- 
mo é dia oito e eu tenho médico na Unicamp eu passo lá, vou sozinho fazer exame do

coração e tudo amanhã, tudo eu faço sozinho pago as minhas contas sozinho, recebo sozinho, eu acho que empoderamento é isso na minha vida. Eu participo de várias atividades como estar conversando com você aqui tranquilo independentemente [...] então eu acho empoderamento em minha vida é isso. (U3).

[...] aprendi a conhecer os profissionais e conhecer outros usuários, a dificuldade de cada um, a escuta, a gente aprende muita coisa, a gente se empodera com isso. [...] Gente, o ganho não está só no remédio, o ganho está bem além disso, ele é só o fundinho do cone, o disparador, que dispara aquilo lá e o resto você vai pensar. (U6).

De acordo com Silva (2006), o sujeito de desejo, quando tem domínio de si, desenvolve uma arte da existência, determinada pelo cuidado de si. O tema do cuidado de si é trazido por Foucault no início dos anos 1980. Foucault traz o cuidado de si associado às técnicas de si que partem de uma reflexão a respeito da vida de cada sujeito, sobre a maneira de regular a conduta, fixando para si mesmo os fins e os meios, possibilitando o cuidar de si (FOUCAULT, 2004).

Segundo Nardi e Silva (2005), esse cuidado pode ser compreendido como um conjunto de tecnologias e experiências que participam do processo de (auto) constituição e transformação do sujeito. Nessa perspectiva, Revel (2005, p. 33) apresenta a expressão: "cuidado de si", indicando o conjunto das experiências e das técnicas que o sujeito elabora e que o ajuda a transformar-se a si mesmo.

Dar liberdade e informar a gente, porque às vezes as pessoas não entende a gente e a gente deixa de ser livre. Aqui no CAPS eu vinha de perua, de transporte e agora eu vou e volto normal, sozinha. Ah! Muito bom, me sinto melhor, mais independente. (U4).

[...] empoderamento é ter deixado o meu filho mais alegre, não é tão isolado como antes. (F1).

Observamos, a partir desses relatos e da fundamentação de alguns autores, que o empoderamento se apresenta como um cuidado de si representado pela melhora da funcionalidade social, pela mudança de comportamento, a conquista da capacidade de andar sozinha na cidade, dando aos sujeitos a liberdade de ir e vir, trazendo um significado de bem-estar e consequente melhora das condições de vida dos usuários e familiares.

\section{Empoderamento: relacionar, conversar, fazer amizades}

O processo de socialização, para Humerez (1998), é iniciado na família, mas se cumpre quando a pessoa é capaz de perceber que a realidade transcende as fronteiras de sua casa e se espalha para todo o mundo social. É quando ela começa 
a ver que as coisas, os amigos, as pessoas, são diferentes da sua realidade cotidiana e que existe outro mundo além daquele que conhece, existe uma sociedade.

Observamos nessa conceituação que o empoderamento é trazido como uma forma de estimular a socialização dos sujeitos em sofrimento mental, uma ferramenta para a reinserção social.

[...] empoderamento é fazer meu filho se relacionar, conversar, fazer amizades. Hoje ele levanta cedo todo animado, cantando, mudou totalmente a vida dele. Hoje o meu filho, com ajuda do CAPS e das atividades, ele é mais compreensivo, mais obediente, um pouco mais independente e também, vamos dizer assim, que é difícil ter depressão, porque ele tinha muito, muita depressão e hoje é muito difícil. (F1).

Ter poder né, ter poder sobre algo. Empoderamento é você tomar posse de uma circunstância. [...] empoderar é fazer amizade e se sentir bem, meu amigo me empodera, me deixa forte para eu não desistir de vir no CAPS, de participar do movimento e não desistir de me cuidar. (U5).

Não só o serviço que empodera, mas as amizades, as relações, as meninas dá muita atenção, são muito atenciosa com ele. (F3).

Eu acho que a forma como eu entrei na atividade como coordenador, como o responsável pelo desenvolvimento da atividade, isso me fez sentir importante, participando do planejamento e da organização da atividade, apesar de preferir ficar anônimo, mas isso me ajudou muito a ficar mais sociável, porque antes eu era muito ruim. As relações, fazer amizade, a conversa, eu acho, todo mundo fala sua opinião, a conversa do pessoal. Acho que cada um tem a sua opinião, um espaço que o pessoal fale sem medo. Ter interação é importante. (U2).

As relações resultantes do trabalho em saúde mental, pautado na produção de vínculo e acolhimento, surgem a partir do cuidado explícito e às vezes implícito, de forma humanizada e com base numa tecnologia não-material de extrema importância para a satisfação de usuários, familiares e profissionais das unidades. Assim, esse trabalho acontece a partir de "um encontro entre duas 'pessoas', que atuam uma sobre a outra, e no qual opera um jogo de expectativas e produções, criando-se intersubjetivamente, alguns momentos interessantes" (MERHY, 1997, p. 5).

A importância das relações atreladas às falas dos usuários e familiares se faz legítima desde a definição de saúde mental trazida pela Organização Mundial da Saúde como "a capacidade de estabelecer relações harmoniosas com os demais e a contribuição construtiva nas modificações do ambiente físico e social" (ESPINOSA, 1998, p. 16). 
A produção desse saber militante é nova e autoanalítica, individual e coletiva, particular e pública. Esse saber opera e interroga os próprios sujeitos em suas ações protagonizadoras, colocando-lhes desafios e sentidos para seus modos de agir, seja individual ou coletivo (MERHY, 2004).

A relevância do contato, participação e garantia de um espaço de fala nos conselhos de saúde, saúde mental e outras políticas sociais, bem como no desenvolvimento de projetos de pesquisa, planejamento e avaliação de serviços, são trazidos por usuários e familiares como ferramentas importantes em seu processo de empoderamento.

As conferências onde se fala dos serviços do SUS. As CONFERÊNCIAS, o CONTROLE SOCIAL. Controle social fica meio indefinido, mas nas conferências principalmente, onde se deliberam muita coisa, então lá eles... Eu, na maior parte do tempo, fico quieto, porque não gosto de falar em público, mas já vi muitos usuários ficarem empoderados, falar mesmo, participar. (U5).

[...] e desse tempo para cá assim, meu filho está sempre assim, sempre vai, vai para o Rio de Janeiro, vai para onde vai esse negócio de conferência, vai representar Campinas; vai debater sempre a saúde mental em primeiro lugar. As conferências são muito importantes, porque eles falam o que eles sentem, eles procuram sempre fazer de tudo para melhorar a cada dia, um tratamento melhor, um tratamento digno para seres humanos [...]. (F2).

Uma das angústias apontadas pelos entrevistados quando indagados sobre o conceito de empoderamento, além da questão da militância, mas como consequência desta, foi a crítica ao modelo antigo, à lógica manicomial. Como se a própria mudança na lógica de cuidado, com a criação dos serviços substitutivos, representasse uma ferramenta de empoderamento, sobretudo para os familiares que vivem e viveram na pele a dificuldade de lidar com o sofrimento mental.

[...] antigamente era muito triste, meu pai, os familiares de meu pai vieram todos a falecer assim em lugares de psiquiatria, e era muito sofrimento, muito sofrimento porque era na base do "sossega leão", camisa de força, o eletrochoque, que eu também tomei o eletrochoque aos 17 anos de idade e era muito ruim, muito ruim mesmo e hoje a gente está na luta, tanto eu como os familiares e eles mesmos, os usuários. (F2).

[...] na década de 40, 50, 60 e 70 e até na década de 80, quem ficava doente psicologicamente não tinha a palavra, não tinha voz, não tinha identidade; ficava no manicômio até a sua morte ou ficava com sequelas. No meu caso não, eu sou o porta-voz, não só eu como os meus colegas que fazem rádio no Maluco Beleza, somos os porta-voz dos que se calaram por muitos anos. Então para nós é muito legal isso aí, eles estarem ouvindo, apoiarem a reforma psiquiátrica isso é importante. (U3). 
Dessa forma, observamos que o protagonismo começa com a crítica dos lugares que se quer produzir, que se quer modificar, configurando-se em dois lugares possíveis: o de sujeito limitado ou o de sujeito crítico/político, de direito, que debate as formas de cuidado e a instituição, garantindo seu direito de vez e voto e tornando sujeito ativo que interfere no campo político do cuidado, respaldado pelas conferências e conselhos.

\section{Empoderamento: troca de experiências para um ajudar o outro}

A ajuda entre pares, entre os iguais em sofrimento, pauta-se no respeito pela diversidade das pessoas, fortalecendo as capacidades individuais e coletivas, na voluntariedade dos não-profissionais, primando por suas potencialidades, identificando, assim, os recursos para apoiar as pessoas em necessidade (RAPPAPORT, 1990).

Percebe-se com as falas que o empoderamento emerge da prática da coletivização, permitindo ao usuário sair da compreensão individualista de seu problema, colocando-o em contato com outros usuários, apoiando o questionamento das soluções individuais, possibilitando a vinculação e aproximação de pessoas que sofrem, mas que não desistem de lutar por formas melhores de viver.

[...] para ser sincera, depois que eu vim aqui ouvir, conversei, o técnico de referência conversou com a gente, o doutor aqui, mesmo nessas conversas do grupo de família, tudo ajuda, a mente vai abrindo, o caminho da gente vai abrindo, porque só ficar naquilo não dá. Então a gente tem que buscar coisas novas para poder funcionar a mente. (F3).

Para mim, participar do grupo de ajuda mútua é muito importante, ajuda muito, porque eu me achava, assim, a última, porque que eu tive um filho desse jeito. Aí eu vejo que as pessoas também têm outras muito piores. E outra, parece que a gente vai lá e a gente [...] é um desabafo, a gente conversa muito, a gente discute os problemas, tudo. Parece que a gente sai de lá mais leve, mas isso é muito bom para as famílias. (F1).

A ajuda-mútua, dessa forma, concretiza-se pela ação de partilha das situações de vida, em um processo de catarse das dificuldades enfrentadas, através da qual se identificam na vivência subjetiva dos problemas de cada um, possibilitando o conhecimento da experiência individual com o sofrimento mental em si ou com a convivência com alguém que sofre:

O que ajuda a gente é aprender mesmo, é o aprendizado mesmo, porque normalmente a gente já sabe que não é só a gente que tem o problema; muitas pessoas têm os mesmos problemas, então é uma palavra assim que a gente acata que vai servir para a 
gente, nada que eles estão falando é em vão, as experiências, tudo [...]. Não tem nada

em vão, o importante é a gente estar aprendendo para lidar, aprender a lidar. Lidar com os de casa, com os de fora. (F3).

[...] a informação, a troca de experiências para um ajudar o outro, e o aprendizado, isso é importante. (F2).

A partir desses relatos, pudemos desvelar e ratificar uma das proposiçōes do processo de ajuda mútua e coletivização que se configura como espaço de apoio, troca de vivências e convivências, aprendizagem individual e coletiva e, fundamentalmente, experiências construtivas entre pessoas.

\section{Empoderamento para os profissionais}

Ao pensarmos uma estratégia para abordar o tema do empoderamento entre os profissionais, buscávamos algo que possibilitasse um espaço de diálogo, no qual os sujeitos pudessem se expressar e, sobretudo, escutar os outros e a si próprios. Optamos então pela Roda de Conversa, que foi um instrumento motivador na construção da autonomia dos profissionais por meio da problematização, da socialização de saberes e de reflexões voltadas para um melhor cuidado e uma melhor forma de interpretar esse cuidado. Envolveu, portanto, um conjunto de trocas de experiências, de conceitos e pré-conceitos, de discussão, conversas e divulgação de conhecimentos.

Dessa forma, a riqueza da roda de conversa esteve no respeito às singularidades, pois as exposiçõos de conceitos nem sempre convergiram, mas quando divergiram suscitaram reflexões e reavaliações do conceito de empoderamento trazido por cada participante. Para explanar esses conceitos, buscamos apresentá-los em duas categorias: 1) autonomia e responsabilização do sujeito; 2) poder, poder de decisão.

\section{Empoderamento como autonomia/responsabilização do sujeito}

$\mathrm{Na}$ definição de empoderamento, obtivemos como relatos relevantes: a autonomia dos sujeitos, o fato de os usuários serem protagonistas nas tomadas de decisão e se responsabilizarem por seus atos.

Para mim, empoderamento é o quanto a gente pode cuidar do outro, mas esse cuidado para ser integral não precisa você fazer pelo outro, pois devemos dar a ele (usuário) essa autonomia para ele poder aproveitar disso tudo. (PI3). 
Esse cuidar permite aos usuários e familiares o direito a escolhas, valorizando e incentivando ao máximo sua participação em todo processo de cuidado. Portanto, o cuidado deve ser de forma a respeitar a dignidade, a singularidade, a autonomia dos sujeitos:

Acho que é uma forma de responsabilização do sujeito consigo próprio, com a sua vida, de você promover isso. As atividades que têm o empoderamento como objetivo, eu acho que buscam isso, tornar o sujeito mais responsável pela sua vida, em relação aos seus cuidados, enfim. (PM3).

Alguns entrevistados trouxeram em seus relatos, agregada a essa responsabilização, a apresentação da autonomia como a definição de empoderamento, colocando-a como um processo de negação da tutela:

Vejo empoderamento como desenvolvimento de autonomia, pelo menos é a primeira coisa que me vem à cabeça. [...] conseguir com que o sujeito tome conta de seu cotidiano, da sua vida, das suas questóes. Que ele não precise de alguém que o tutele e que ele consiga dar conta das suas questôes de vida, de trabalho, das relações sociais. (PM3).

Assim, o conceito vincula-se à singularidade de cada indivíduo, perpassando sua história de vida e o contexto em que está inserido. Salienta a potencialidade dos sujeitos serem protagonistas no enfrentamento dos problemas cotidianos, de modo a nele interferir uma relação que permite construir soluções para as dificuldades e os problemas que se apresentam.

Em outro olhar, o empoderamento é trazido como autonomia, mas

Pensando em autonomia não na perspectiva da pessoa ser ou não, mas pensando em grau de autonomia, entendendo que a gente nas relações humanas e nas relações da vida a gente sempre tem um menor ou maior grau de autonomia, mas nunca é totalmente autônomo e que essa construção de autonomia é sempre coletiva, pensando nessa questão da autonomia como a capacidade que o indivíduo tem de gerar a ordem - enfim, relações para a própria vida. (PM4).

Esses conceitos articulam indivíduos e sociedade, uma vez que os remetem a uma rede de relaçooes sociais. Considera-se como autônomo aquele que se articula ao maior número de relações sociais, tendo também a consciência de que cada sujeito constrói uma rede diferenciada de relaçóes sociais individuais (MOREIRA; ANDRADE, 2003).

[...] então, quando me vem à questão do empoderamento me vem muito em pensar junto com o usuário a construção de maiores graus de autonomia de uma rede cada vez maior de relações e que aí a rede de dependência deixa de ser a dependência no sentido clássico do termo, mas quanto maior a rede de dependência, maior a capacidade e maior o grau de autonomia a pessoa pode ter, porque maior é o número de variáveis que a gente pode lidar. (PM4). 
De acordo com Kynoshita (2001), para tornarmos autônomos, precisamos ser capazes de estabelecer contratos sociais. Essas condiçóes nos levam a criar novas normas para as diversas situações enfrentadas.

Com esse olhar, verificamos que a participação do sujeito e o reconhecimento dos direitos de todos em concordar e/ou discordar das condições de vida, implica desafios, mas estes se tornam empoderadores para os usuários e familiares à medida que potencializam e impulsionam a autonomia e a emancipação. Então o empoderamento, para legitimar essa autonomia, incorpora a noção de participação e o direito a se ter uma opinião, seja para discordar ou concordar:

[...] participação nas tomadas de decisões. Com isso vêm também as discordâncias no sentido de poder discordar quem quer que seja, ou concordar que seja, porque nem sempre a gente trabalha só com discordância, as diferenças, nesse sentido. Acho que vem, a princípio, participação na tomada de decisão. (PI2).

Podemos verificar que, na definição de empoderamento como autonomia, responsabilização e participação dos sujeitos nas tomadas de decisões, configuramos um indivíduo que não se mantém refém de determinações únicas, que é capaz de estabelecer relações pessoais e sociais em diversos lugares, diversos contextos e, muitas vezes, ser protagonista destas, montando redes diferenciadas de suporte, redes potentes de cuidado e apoio sempre que necessário.

\section{Empoderamento como poder}

Apesar da fragmentação do conceito de empoderamento, não podemos deixar de salientar a complementaridade de cada dimensão de sua interpretação, pois sua definição é complexa e multifacetada.

A palavra para mim é nova, mas assim, a gente tem uma noção que a própria palavra traz que é poder. Eu acho que até tornar a pessoa capaz de entender melhor o mundo e a gente, como sujeito. (PM3).

Nesse sentido, o poder mostra-se como a raiz da autonomia, permitindo-nos montar as partes para moldar seu entendimento (LABONTE apud BERNSTEIN et al., 1994).

Empoderamento lembra poder, poder na capacidade de realização das atividades do dia a dia, em condição da própria vida; [...] poder que atua na autonomia dos usuários quanto as suas escolhas. (PM1).

O empoderamento perpassa o ganho de poder que permite aos indivíduos direcionar suas proposições e gerar mudanças. Uma forma de aumentar o poder 
pessoal é identificar e compreender o poder que já possui. Envolve a capacidade de fazer escolhas para a vida e agir sobre elas. Com esse foco, o entrevistado traz em sua fala que o empoderamento:

[...] é um poder de tomada de decisão, de iniciativa, de autonomia, de capacidade de enfretamento das dificuldades, de recurso interno de enfrentamento dessas dificuldades; é de poder fortalecer os usuários na sua decisão, abrir um pouco mais o leque de possibilidade de escolha e aí enfim, que ele possa escolher, decidir, ter mais autonomia para fazer as coisas da vida e se fortalecer enquanto recursos, em saber quais são os recursos que ele tem e ai desenvolver alguns outros. (PM1).

Fazendo um contraponto com essa colocação, em outra abordagem pudemos observar uma discussão sobre as dimensões de poder existentes no cotidiano, que algumas vezes se caracteriza como domínio de poder, definindo o empoderamento como fazer uso do poder como profissional na estratégia de cuidado e proteção.

Empoderar é tomar posse; poder de contratualidade. Eu acho que assim, na hora que faz uso da medicação, muitas vezes o paciente não quer tomar, aí você vai lá e por ter poder de dar medicação, o dá à força. Outra hora é no portão, o paciente quer ir embora, não quer ficar no serviço e você está empoderando quando você que tem o poder não o deixa sair e com isso nós que estamos empoderando eles, tipo a gente está fazendo por eles, o que ele não quer. (PM2).

Esse comportamento, de acordo com Teixeira (2002), significa dar poder ao outro, compartilhando alguns poderes que os profissionais, assim como outras lideranças dos serviços ou grupos comunitários devem ter sobre outros. Essas pessoas são vistas como agentes de empoderamento e como sujeitos do relacionamento, e permanecem como sendo os atores controladores, definindo os termos da interação. Os indivíduos ou grupos relativamente desempoderados permanecem como objetos da relação, como o receptor da ação do profissional/ liderança, numa atitude passiva.

Entretanto, a exposição da fala, na entrevista citada acima, possibilitou ao grupo debater esse conceito, respeitando a singularidade de cada um, mas suscitando o contraponto trazido na fala abaixo, que apesar da incerteza, expressou o seu ponto de vista próprio, acreditando em um conceito diferente.

Eu não sei, mas eu acho que empoderar é fazer o contrário disso. É fazer a vontade do usuário e não a da equipe. É empoderar o paciente, ter mais autonomia, decidir pelas coisas dele, e não a gente fazer isso por ele. (PM2).

Essa discussão, acerca das diferentes percepções de empoderamento, tornou possível emergir a riqueza do debate e relembrar a todos a importância de refletir 
as práticas na saúde mental, na busca de consensos de equipe, no repensar das ações. Desse consenso, tivemos o seguinte relato:

$\mathrm{Na}$ verdade, empoderamento é a gente poder transitar entre esses dois momentos, assim, mas que seja uma negociação junto com ele (usuário), um projeto que a gente construa junto, a ponto de que o usuário então possa chegar e dizer: 'olha eu vou, mas vou tomar uma (cachaça, cerveja...), eu não vou chegar aqui bêbado, eu vou tomar um gole’. Eu acho que são atividades na verdade que a gente constrói junto com o usuário, com a possibilidade de uma vida mais autônoma e mais, que seja decidida por ele, não mais por mim e que talvez por ele seja diferente do que seja por mim” (PM2).

Costa-Rosa et al. (2003) utilizam essa abordagem, compreendida na relação técnico-instituição-sujeito, quando definem contratualidade social, que é a condição de estabelecer contratos sociais de reciprocidade e de trocas, de se responsabilizar pela própria decisão e de ser capaz de enfrentar, aos poucos, as adversidades da vida.

Destacamos, dessa forma, como fator relevante das discussões apresentadas, o entendimento de empoderamento como uma conotação de valor baseada na conceituação de poder compartilhado, ao invés do poder sobre o outro. Ao mesmo tempo, de acordo com a dimensão de empoderamento como fortalecimento dos sujeitos, trazido por Moreau, abordamos a importância de tornar explícita a relação de poder na intervenção profissional, por exemplo, fazendo um contrato claro com os usuários, compartilhando com eles as informações e as técnicas, clarificando os papéis de cada um (FALEIROS, 2007). Esse poder compartilhado proporciona e reforça a autonomia tão buscada e trazida pelos sujeitos como conceito de empoderamento.

A partir deste ponto, em que já descrevemos a singularidade e a subjetividade do conceito de empoderamento trazido por usuários, familiares e profissionais, iremos realizar uma comparação das várias visões categorizadas.

\section{Comparando as visões dos diferentes atores}

Fazer essa comparação entre as visões dos diferentes atores constitui uma tarefa difícil, pois nos deparamos com as múltiplas facetas do conceito de empoderamento, que se remetem à própria complexidade dos fenômenos associados às relações de poder e às diferentes perspectivas em que são vistas e vividas pelos diferentes atores sociais, particularmente quando envolve o sofrimento mental, que pode implicar nos períodos mais críticos da crise em uma relativa perda cognitiva e da 
capacidade de tomar decisões de forma responsável. Porém, pudemos constatar particularidades nas formas em que é vivido na prática por usuários e familiares e o que é obtido na formação e exercitado na prática profissional, que potencialmente pode levar a uma lógica diferente de cuidado, tornando o usuário singular em seu processo de reinserção e ressignificação da vida.

As visões do conceito misturaram-se em seus muitos sentidos, sendo trazidos de forma mais simplificada pelos usuários e familiares, baseada nos ganhos diários de reinserção, de fortalecimento, de adaptações, mudanças e evoluçõos que os levaram a viver e conviver melhor. Os profissionais se colocam de forma mais embasada teoricamente, na lógica do cuidado integral, humanizado, pautado no protagonismo dos sujeitos, levando-os, em momentos, ao empoderamento e a responsabilização do próprio cuidado.

Vemos com isso que a palavra "cuidado", seja ela o cuidado de si apontado pelos usuários ou o cuidado proposto pelos profissionais, perpassa o conceito de empoderamento como um cuidado que não é simplesmente ofertado, nem desfrutado, mas problematizado e feito para além do cuidado em si, mas com o propósito de fazer junto, profissional, usuário e familiar, e permitir o protagonismo, almejando a corresponsabilização.

E pudemos, no decorrer dos conceitos e falas, visitar outras categorias que complementam o conceito e que buscam também um cuidado, como a ajuda mutua/coletivização. Falamos aqui de um cuidado estendido ao outro, a um “igual”, que muitas vezes é mais capaz de compreender empaticamente seu sofrimento psíquico do que um profissional. Nesse processo, percebemos o lugar do usuário e do familiar como protagonistas desse cuidado, que se baseia na troca de experiências e na participação de cada ator como protagonista de sua vida, de suas histórias e peças importantes na reflexão e mudança de comportamento de cada um que ver no outro um agente empoderador.

Se continuarmos pensando em termos de contato, podemos abarcar, ainda, a própria militância, que continuaria sendo um cuidado consigo e com o outro "semelhante", de forma politizada. Quando um sujeito luta política e coletivamente pelos seus direitos, ele também está lutando pelo outro que ele sequer conhece, uma vez que a opção é lutar por um conjunto e não apenas pelos seus interesses individuais. Quando se critica e condena as formas de cuidado "descuidado" antes utilizado e por eles experimentado -, luta-se para que outras 
pessoas não experimentem aquilo. Essa luta pelo outro só é alcançada se for permitido ao usuário e familiar estar à frente da decisão de como se cuidar, de como gostariam de ser cuidados, direcionando o foco tanto de militância quanto de crítica ao modelo manicomial, possibilitando assim a autonomia do sujeito.

Entendemos o conceito de empoderamento apresentado pelos profissionais vislumbrando a autonomia dos sujeitos, perpassando o poder de escolha, poder de decisão e poder de serem sujeitos com as suas diversidades e semelhanças. Nesse desenrolar de sentidos, vemos que os profissionais apontam como ferramenta para tornar os usuários empoderados à presença da autonomia em todo transitar do usuário, não apenas isolado nos serviços, mas na sociedade. Essa autonomia permite aos usuários e familiares o direito de escolha, o direcionamento de seu cuidado e, principalmente, a ressignificação do estar do usuário nas relações, entre as pessoas e em sociedade.

\section{Considerações finais}

Apesar de o termo "empoderamento" na saúde mental ser algo recente, foi surpreendente adentrar um campo de pesquisa onde usuários, familiares e profissionais pautavam seu entendimento de cuidado nessa lógica empoderadora, trazida tanto na literatura quanto nas falas dos entrevistados como fator primordial para alcançar o objetivo da Reforma Psiquiátrica.

Dar vazão aos desejos e anseios dos usuários e familiares, por meio da voz e da escuta, permite-nos conhecer por dentro o sofrimento e entender o porquê da necessidade de estes estarem à frente do cuidado e da própria vida. Assim, o papel dos profissionais surge não como controlador dos usuários e/ou familiares, mas como cotransformadores de suas vidas, pela colaboração no processo de fortalecimento do poder e da autonomia de cada sujeito. E o maior ganho como pesquisadora está em constatar que é possível ter esperança de mudar a realidade no campo da saúde, por ter vivenciado serviços e conhecido pessoas que extrapolam as linhas teóricas e legais direcionadoras do cuidado e as póem de fato em prática.

Sendo assim, os resultados apresentados aqui nos remetem à necessidade de discussão e reflexão, em cada serviço de saúde mental, por cada profissional que se propõe a cuidar e acompanhar usuários e familiares em sofrimento mental, pois sabemos da existência de serviços ditos substitutivos e profissionais que tentam 
ser militantes, mas que acabam reproduzindo as práticas dominantes, caindo na contradição teoria-prática e anulando, por vezes, os sujeitos de seus direitos básicos como cidadãos. No entanto, a experiência obtida com a pesquisa nos permite afirmar que é possível desenvolver um trabalho pautado na participação dos sujeitos, na busca da sua autonomia em todo processo de cuidado com o intuito de ter os serviços não como o único lugar de estar e se tratar, mas como espaços do qual emergem pessoas críticas e lutadoras por seus direitos e lugares na sociedade.

Pudemos identificar, então, o empoderamento não apenas nas ações propostas pelos profissionais, nas falas de empoderamento dos entrevistados, mas sobretudo nas mudanças de vida de usuários e familiares. E nessa construção partilhada emergiram sujeitos antes tidos como incapazes, dependentes, "loucos”, mas que hoje são reconhecidos como representantes da cidade, protagonistas das ações de lutas e enfrentamentos das barreiras impostas pela sociedade, pessoas que precisavam apenas de um olhar, uma sensibilidade para fortalecer suas potencialidades.

Assim, pretendemos disseminar a importância de uma filosofia empoderadora embutida no olhar do cuidador e na visão de quem é cuidado, possibilitando irmos além das patologias, das limitações, das inseguranças, dos medos, focando nas potencialidades e no desejo partilhado entre usuário, família e profissional de superar as dificuldades. ${ }^{2}$

\section{Referências}

BERNSTEIN, E. et al. Empowerment Forum: a dialogue between guest editorial board members. In: Health Education Quarterly. Special issue: Community empowerment, participatory education and health - Part II, v. 21, n. 3, p. 281-294, 1994.

BRASIL. Conferência Regional de Reforma dos Serviços de Saúde Mental: 15 anos depois de Caracas. Ministério da Saúde. Reforma Psiquiátrica e Politica de Saúde Mental no Brasil. Brasília, 07-10 nov 2005. Disponível em: <http://bvsms.saude.gov.br/bvs/publicacoes/ Relatorio15_anos_Caracas.pdf> Acesso em: 04 mar. 2011.

BRASIL. Ministério da Saúde. Secretaria de Vigilância em Saúde. Política Nacional de Promoção da Saúde. Brasília: Ministério da Saúde, 2006.

BRASIL. Sistema Único de Saúde. Conselho Nacional de Saúde. Comissão Organizadora da IV Conferência Nacional de Saúde Mental. Relatório Final da IV Conferência Nacional de Saúde Mental - Intersetorial, 27 jun a 01 jul 2010. Brasília: Conselho Nacional de Saúde, 2010, 210 p. 
COSTA-ROSA, A.; LUZIO, C. A.; YASUI, S. Atenção Psicossocial: rumo a um novo paradigma na Saúde Mental Coletiva. In: AMARANTE, P. D. (Coord.). Archivos de Saúde Mental e atenção psicossocial. Rio de Janeiro: NAU, 2003, p.13-44.

SPINOSA, A. F. Guias práticos de enfermagem: Psiquiatria. Rio de Janeiro: McGraw-Hill, 1998. FALEIROS, V. P. Estratégias em serviço social. São Paulo: Cortez, 2007.

FLEURY, S. M. T. Reforma sanitária brasileira: dilemas entre o instituinte e o instituído. Ciência \& Saúde Coletiva, v. 14, n. 3, p. 743-752, 2009.

FOUCAULT, M. A ética do cuidado de si como prática da liberdade. In: Ditos \& Escritos V-Ética, Sexualidade, Política. Rio de Janeiro: Forense Universitária, 2004, p. 264-287.

FREIRE, P. Conscientização: teoria e prática da libertação. Rio de Janeiro: Paz e Terra, 1980. HUMEREZ, D. C. História de Vida: instrumento para captação de dados na pesquisa qualitativa. São Paulo: EdUSP, 1998.

KINOSHITA, R. T. Contratualidade e Reabilitação Psicossocial. In: PITTA, A. (Org.). Reabilitação Psicossocial no Brasil. São Paulo: Hucitec, 2001, p. 55-59.

LAVERACK, G.; LABONTE, R. A planning framework for community empowerment goals within health promotion. Health Policy Plan, v. 15, n. 3, p.255-262, 2000.

MERHY, E. E. O conhecer militante do sujeito implicado: o desafio de reconhecêlo como saber válido. In: FRANCO, T. B.; PERES, M. A. A. (Orgs.). Acolher Chapecó. Uma experiência de mudança do modelo assistencial, com base no processo de trabalho. São Paulo: Hucitec, 2004, v. 1, p. 21-45. Disponível em: < www.uff.br/saudecoletiva/ professores/merhy/capitulos-02.pdf > Acesso em: 22 jun. 2012.

MERHY, E. E. A perda da dimensão cuidadora na produção da saúde: uma discussão do modelo assistencial e da intervenção no seu modo de trabalhar a assistência. Campinas: Unicamp, 1997.

MOREIRA, M. I. B.; ANDRADE, A. N. Ouvindo Loucos: construindo possibilidades de viver com autonomia. Psicologia, Saúde e Doenças, v. 4, n. 2, p. 249-266, 2003.

NARDI, H. C.; SILVA, R. N. Ética e subjetivação: as técnicas de si e os jogos de verdade contemporâneos. In: GUARESCHI, N.; HÜNINNG, S. M. (Orgs.). Foucault e Psicologia. Porto Alegre: Abrapso Sul, 2005.

NEVES, E. T.; CABRAL, I. E. Empoderamento da mulher cuidadora de crianças com necessidades especiais de saúde. Texto Contexto Enfermagem. Florianópolis, v. 17, n. 3, p. 552-60, jul-set 2008.

OLABUENAGA, J. I. R.; ISPIUZA, M. A. La descodificacíon de la vida cotidiana: métodos de investigacíon cualitativa. Bilhão: Universidade de Deusto, 1989. 
RAPPAPORT, J. Desinstitucionalização: empowerment e interajuda. O papel dos técnicos de saúde mental no século XXI. Análise Psicológica, v. 8, n. 2, p. 143-162, 1990.

REVEL, J. Michael Foucault conceitos essenciais. São Carlos: Clara Luz, 2005.

SANT'ANA, R. B. A autonomia do sujeito: as contribuições teóricas de G. H. Mead. Psicologia: Teoria e Pesquisa, v. 25, n. 4, p. 467-477, out-dez 2009.

SILVA, S. M. A Vida como uma Obra de Arte. Revista Científica/FAB. Curitiba, v. 2, p. 1, 2006. TEIXEIRA, M. B. Empoderamento de idosos em grupos direcionados à promoção da saúde. 2002, 144p. Dissertação (Mestrado em Saúde Pública) - Escola Nacional de Saúde Pública Departamento de Administração e Planejamento em Saúde, Fundação Oswaldo Cruz, Rio de Janeiro, 2002.

VASCONCELOS, E. M. O poder que brota da dor e da opressão: empowerment, sua história, teorias e estratégias. São Paulo: Paulus, 2003.

VASCONCELOS, E. M. (Org.). Abordagens psicossociais. V. II: Reforma psiquiátrica e saúde mental na ótica da cultura e das lutas populares. São Paulo: Hucitec, 2008.

WENDHAUSEN, A. L. P.; BARBOSA, T. M.; BORBA, M. C. Empoderamento e recursos para a participação em Conselhos Gestores. Saúde e Sociedade. Rio de Janeiro, v. 15, n. 3, p. 131-144, set-dez 2006.

\section{Notas}

${ }^{1}$ Artigo produzido tendo por base a dissertação de mestrado em Saúde Coletiva intitulada Dispositivos de Empoderamento em Saúde Mental em um Centro de Atenção Psicossocial no Brasil (ALVES, 2012).

${ }^{2}$ T.C.Alves participou da coleta de dados, análise dos dados e redação do artigo. W.F. Oliveira orientou a pesquisa que originou o artigo e revisou a análise dos dados. E.M. Vasconcelos co-orientou a pesquisa, participou da discussão e análise dos dados, e da redação deste trabalho. 


\section{Abstract}

\section{The viewpoint of users, families and professionals about empowerment in mental health}

This study sought to investigate the concept of empowerment recognized by the main actors involved in mental health care in two psychosocial care services as a way to contribute to the evaluation of the identification, characterization, and ownership of empowerment devices in the Brazilian psychiatric reform. As a field of research, we selected a Center for Psychosocial Care and a Conviviality Center, both in Campinas city, State of São Paulo, Brazil, performing data collection after the approval of the Ethics Committee of Santa Catarina Federal University. The study subjects were seven users, three family members and 24 professionals from the multidisciplinary team. The case study was descriptive and qualitative. As a result, we found that the concept of empowerment submitted by users, families and professionals glimpses user's and family's autonomy, going through the power of choice, decision-making power and the power of being subject to their differences and similarities. We hoped this work contributes to the understanding of the importance of empowerment in the rehabilitation of people in mental distress, serving as a possible path to modify the realities of care developed in CAPS throughout Brazil.

> Key words: empowerment; devices; mental health. 